\title{
New Rod-Like H-Bonded Assembly Systems: Mesomorphic and Geometrical Aspects
}

\author{
Laila A. Al-Mutabagani ${ }^{1}$, Latifah Abdullah Alshabanah ${ }^{1}$, Hoda A. Ahmed 2,3,*(D), \\ Khulood A. Abu Al-Ola ${ }^{4}$ and Mohamed Hagar ${ }^{3,5, *}$ \\ 1 Chemistry Department, College of Science, Princess Nourah bint Abdulrahman University, \\ Riyadh 11671, Saudi Arabia; laalmutbagani@pnu.edu.sa (L.A.A.-M.); laalsabanah@pnu.edu.sa (L.A.A.) \\ 2 Department of Chemistry, Faculty of Science, Cairo University, Cairo 12613, Egypt \\ 3 Chemistry Department, College of Sciences, Yanbu, Taibah University, Yanbu 30799, Saudi Arabia \\ 4 Chemistry Department, College of Sciences, Al-Madina Al-Munawarah, Taibah University, \\ Al-Madina 30002, Saudi Arabia; kabualola@taibahu.edu.sa \\ 5 Chemistry Department, Faculty of Science, Alexandria University, Alexandria 21321, Egypt \\ * Correspondence: ahoda@sci.cu.edu.eg (H.A.A.); mhagar@taibahu.edu.sa (M.H.)
}

Received: 27 August 2020; Accepted: 5 September 2020; Published: 8 September 2020

\begin{abstract}
Experimental and geometrical approaches of new systems of mesomorphic 1:1 supramolecular H-bonded complexes (SMHBCs) of five rings are discussed. The H-bonding between 4-alkoxyphenylimino benzoic acids (An, as proton acceptor) and 4-(4'-pyridylazophenyl) $4^{\prime \prime}$-alkoxybenzoates (Bm, as proton donor) were investigated. Mesomorphic behaviors were analyzed by differential scanning calorimetry (DSC) and mesophase textures were identified by polarized light microscopy (POM). H-bonded assembly was established by FT-IR spectroscopic measurements via Fermi band discussion. Thermal and theoretical factors were predicted for all synthesized complexes by density functional theory (DFT) predictions. The results revealed that all prepared complexes were monomorphic, with a broad range of smectic A phases with a high thermal stability of enantiotropic mesophase. Furthermore, DFT stimulations illustrated the experimental results in terms of the influence of the chain length either of the acid or the base component. Many parameters, such as the calculated stability, the dipole moment and the polarizability of the H-bonded complexes, illustrate how these parameters work together to enhance the smectic mesophases with the obtained stability and range.
\end{abstract}

Keywords: supramolecular H-bonding complexes; rod-like liquid crystals; mesomorphic behavior; geometrical aspects

\section{Introduction}

Supramolecular hydrogen-bonding liquid crystal complexes (SMHBLCs) were first made in the 20 th century [1]. The first reported SMHBLC dimers were made between 4 - $n$-alkoxycinnamic acids and 4- $n$-alkoxybenzoic acids that showed stable smectic and nematic mesophases [2-4]. A huge number of liquid crystalline materials have been investigated using different synthetic methods, however, the design of SMHBLCs through intermolecular interactions between complementary components are of great interest. The types of interactions might be H-bonding [5-7] or halogen bonding [8-13] and both have the advantage of easy accessibility compared to covalently bonding liquid crystals.

Thermotropic LCs based on intermolecular hydrogen bond interactions are mostly used in display devices and sensor applications [14-18]. Molecular geometry in LC H-bonded complexes can be assembled between different conformations depending on the investigated hydrogen bond donors and acceptors. Recently, several SMHBLCs were formed using different types of H-donors and 
H-acceptors to afford varied varieties of structural geometries, such as rod-like complexes $[19,20]$, angular complexes [21-24] polymeric architectures [25], modular hierarchical complexes [26] and non-symmetric dimers possessing nematic mesophases [27] or showing the heliconical twist-bend nematic phase [28] or supramolecular polycatenars of chiral cubic phases [29]. Modification of efficient materials to be in a novel architecture is an attractive area of interest [30-32].

Azo and azomethine-functionalized LC linkers are of great interest for the technology of light-responsive compounds [33-35]. Later, more types of azobenzene and azomethine-based LCs were reported [36-42]. Azopyridines are of research interest since they possess the ability of assembly by intermolecular H-bonding and the unique property of trans-cis photo-isomerization and thermal isomerization because of the existence of the azo linkage. In addition, calamitic Schiff base liquid crystals possess a unique mesomorphic character [43].

Recently, many researchers [5,31,44-54] have reported the mesophase characteristics of new supramolecular H-bonded complexes (SMHBCs) between acids and pyridines as base one $[55,56]$. In order to better understand the structural effect relationship of SMHBC-based azopyridines, two groups of $\mathrm{H}$-bonded complexes (1:2) based on pyridine as the $\mathrm{H}$-acceptor were investigated [55,57,58]. In another study, the 1:1 SMHBCs prepared between the nitrogen atom of the azomethine derivative and 4-alkoxybenzoic acids [59] has been reported and characterized. In recent research, it has been described [60] that the mesomorphic properties and geometrical expectations can be impacted in a different way by exchanging the azo core group in the base part with an azomethine one [59]. These findings have encouraged us to study the preparation and analysis of another SMHBC based on the azo and azomethine calamitic derivatives. Furthermore, the mixing of computational simulations of geometrical calculations with experimental findings is also interesting [55,61-63] and, in our studies concerning SMHBCs, new calamitic SMHBCs based on the H-bonding interaction between the proton donor, 4-alkoxyphenylimino benzoic acids [45] (An), and the proton acceptor, 4-(4'-pyridylazophenyl) $4^{\prime \prime}$-alkoxybenzoates [19] (Bm), were prepared. The study aims to examine their mesomorphic characteristics and their geometrical parameters by density functional theory (DFT) simulation. Moreover, this study aims to correlate the experimental outcomes of the mesomorphic properties with their estimated thermal and geometrical outcome values.

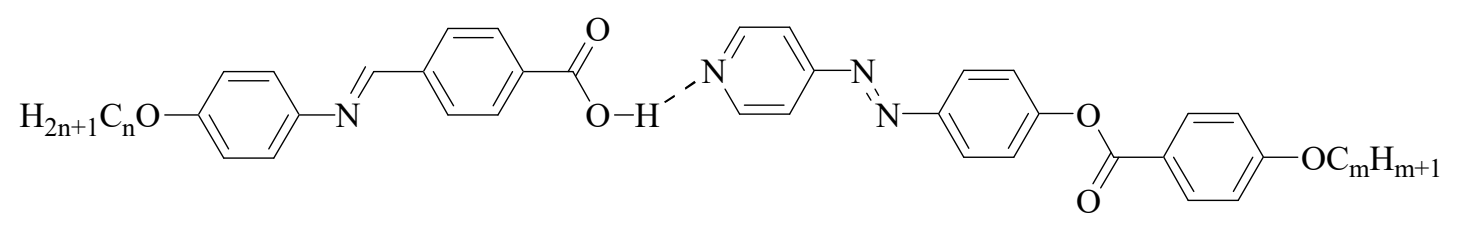

$\mathbf{A n} / \mathbf{B m} ; n=6,8$ and $16 ; m=10,12$ and 14 .

\section{Experimental}

The acid An and the base $\mathbf{B m}$ and their complexes $\mathbf{A n} / \mathbf{B m}$ were prepared according to the following Scheme 1: 


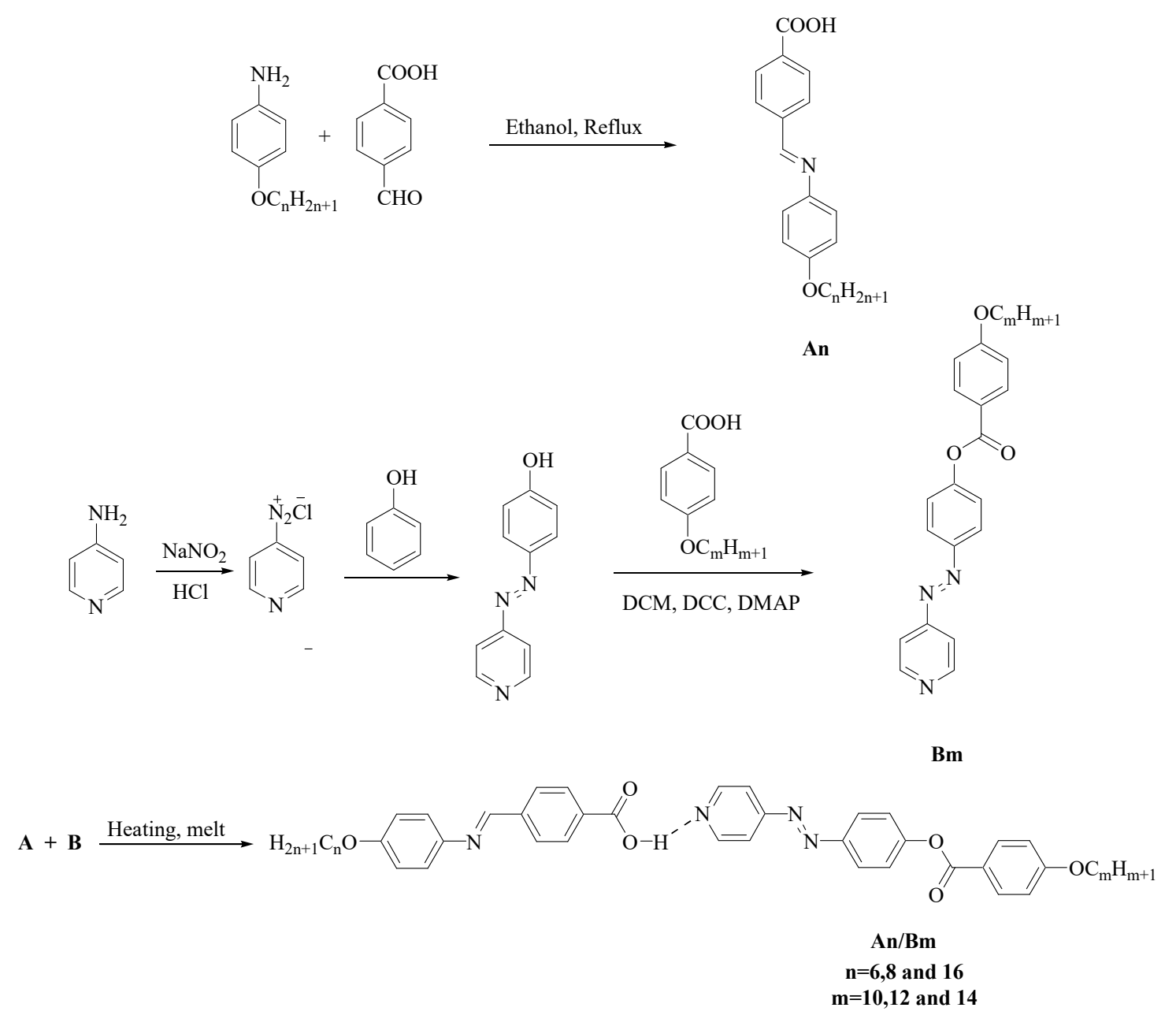

Scheme 1. Preparation of the acid An, the base Bm and their complexes An/Bm.

\section{Preparation of Complexes $\mathbf{A n} / \mathbf{B m}$}

The acid An and the base $\mathbf{B m}$ were prepared according to the previous reported methods in [64] and [19], respectively. Supramolecular complexes An/Bm were synthesized by mixing 1:1 molar ratios of alkoxy Schiff acids (An) with different chain lengths of $n=6,8$ and 16 and the azo base (B) with alkoxy chain lengths $m=10,12$ and 14. The mix was melted with stirring till the intimate blend, then allowed to cool, as shown in Scheme 1. The characteristics of the prepared supramolecular complexes (An/Bm) were studied by differential scanning calorimetry (DSC) measurements, as well as FT-IR spectroscopy (see Supplementary Materials).

\section{Results and Discussion}

\subsection{FT-IR Characterizations}

The formation of the supramolecular complexes An/Bm was proved via FT-IR, X-ray and NMR spectral analysis [65-69]. However, FT-IR measurements proved to be an effective tool for such confirmation [40,60,69-71]. The spectral data were measured for the individual compounds A6, B12 and their complex A6/B12 and are given in Figure 1. 

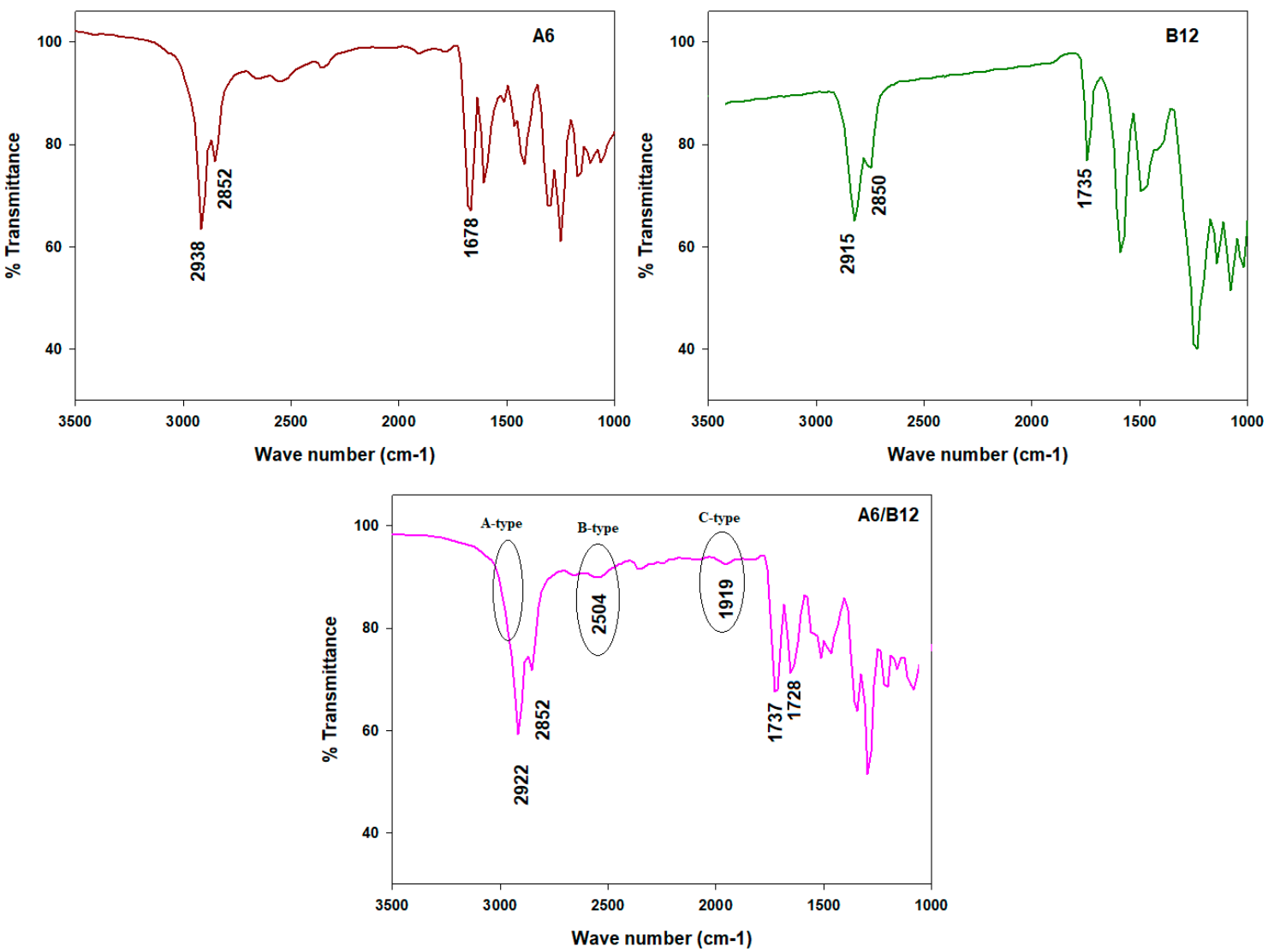

Figure 1. FT-IR spectra of A6, B12 and 1:1 supramolecular H-bonded complex (SMHBC) A6/B12.

As shown in Figure 1, the peak at $1678 \mathrm{~cm}^{-1}$ was attributed to $\mathrm{C}=\mathrm{O}$ groups of the dimeric the alkoxy Schiff acid A6. On the other hand, the ester linkage $\mathrm{C}=\mathrm{O}$ group of the base $\mathbf{B 1 2}$ appeared at $1735 \mathrm{~cm}^{-1}$. The replacement of the dimeric H-bond between the alkoxy acid $\mathbf{A} \mathbf{6}$ and the nitrogen atom of the base (B12) affects the strength of the $\mathrm{C}=\mathrm{O}$ of either the acid or the base, and consequently, their stretching vibration is affected. This information could be proved by the FT-IR spectral data. The new $\mathrm{H}$-bonding decreases the $\mathrm{C}=\mathrm{O}$ stretching vibration of the ester linkage of the base $\mathbf{B} 12$ to $1728 \mathrm{~cm}^{-1}$, however, it increases that of the $\mathrm{C}=\mathrm{O}$ of the $\mathrm{COOH}$ group of the alkoxy acid $\mathrm{A} 6$ to $1737 \mathrm{~cm}^{-1}$.

One of the important reported proofs of the SMHBC formation is the $\mathrm{OH}$ Fermi vibrational stretching bands $[28,69-74]$. It has been reported that the existence of the three Fermi resonance stretching vibration peaks, A-, B- and C-type, of the H-bonded $\mathrm{OH}$ functional group is a proof for the formed SMHB complex. The Fermi peak of the A-type of the complex A6/B12 was below the C-H vibrational frequency at 2922 to $2852 \mathrm{~cm}^{-1}$. Moreover, the band at $2504 \mathrm{~cm}^{-1}$ (A6/B12) is attributed to the B-type of the in-plane bending stretching vibration of the O-H. On the other hand, the $1919 \mathrm{~cm}^{-1}$ peak of the $\mathbf{C}$-type Fermi band is due to the interaction between the overtone of the torsional influence and the essential influence of the $\mathrm{OH}$ stretching vibration.

\subsection{Mesomorphic and Optical Studies}

Mesomorphic behaviors for the present 1:1 SMHBCs (An/Bm) were investigated. Phase transition temperatures $(\mathrm{T})$, associated enthalpy $(\Delta \mathrm{H})$ and their normalized entropy $(\Delta \mathrm{S} / \mathrm{R})$, as well as the mesomorphic range based on DSC measurements for all prepared SMHBCs, An/Bm, are summarized in Table 1. Examples of DSC cycles upon second heating and cooling scans are depicted in Figure 2. In addition, a textural observation example under polarized light microscopy (POM) is represented in Figure 3. A graphical representation of the chain length/transition temperature dependences of the 
characterized complexes is illustrated in Figure 4, in order to study the effect of the length of alkoxy acid and base chains on the mesomorphic characteristics.

Table 1. Phase transitions: temperatures $\left(\mathrm{T},{ }^{\circ} \mathrm{C}\right)$, enthalpy $(\Delta \mathrm{H}, \mathrm{kJ} / \mathrm{mol})$, normalized entropy $(\Delta \mathrm{S} / \mathrm{R})$ and mesomorphic range $(\Delta \mathrm{T})$ for the SMHBCs $\mathbf{A n} / \mathbf{B m}$.

\begin{tabular}{ccccccc}
\hline System & $\mathbf{T}_{\text {Cr-SmA }} *$ & $\Delta \mathbf{H}_{\text {Cr-SmA }} *$ & $\mathbf{T}_{\text {SmA-I }}$ & $\Delta \mathbf{H}_{\text {SmA-I }}+$ & $\Delta \mathbf{S}_{\text {SmA-I }} / \mathbf{R}$ & $\Delta \mathbf{T}_{\text {SmA }}$ \\
\hline $\mathbf{A 6 / B 1 0}$ & 135.4 & 41.61 & 255.6 & 6.85 & 1.56 & 120.2 \\
\hline $\mathbf{A 6 / B 1 2}$ & 136.8 & 54.54 & 243.2 & 8.17 & 1.90 & 106.4 \\
\hline $\mathbf{A 6 / B 1 4}$ & 128.8 & 48.39 & 225.3 & 5.93 & 1.43 & 96.5 \\
\hline $\mathbf{A} 8 / \mathbf{B 1 0}$ & 147.4 & 62.98 & 237.5 & 6.68 & 1.57 & 90.1 \\
\hline $\mathbf{A 8 / B 1 2}$ & 148.3 & 55.51 & 234.8 & 6.77 & 1.60 & 86.5 \\
\hline $\mathbf{A 8 / B 1 4}$ & 129.0 & 54.47 & 230.7 & 5.59 & 1.33 & 101.7 \\
\hline $\mathbf{A 1 6 / B 1 0}$ & 127.1 & 67.13 & 227.1 & 9.05 & 2.18 & 100.0 \\
\hline $\mathbf{A 1 6 / B 1 2}$ & 128.7 & 66.73 & 226.0 & 8.81 & 2.12 & 97.3 \\
\hline $\mathbf{A 1 6 / B 1 4}$ & 125.3 & 71.04 & 215.1 & 7.08 & 1.74 & 89.8 \\
\hline
\end{tabular}

* Cr-SmA = crystal to smectic A phase transition; + SmA-I = smectic A phase to isotropic liquid transition.
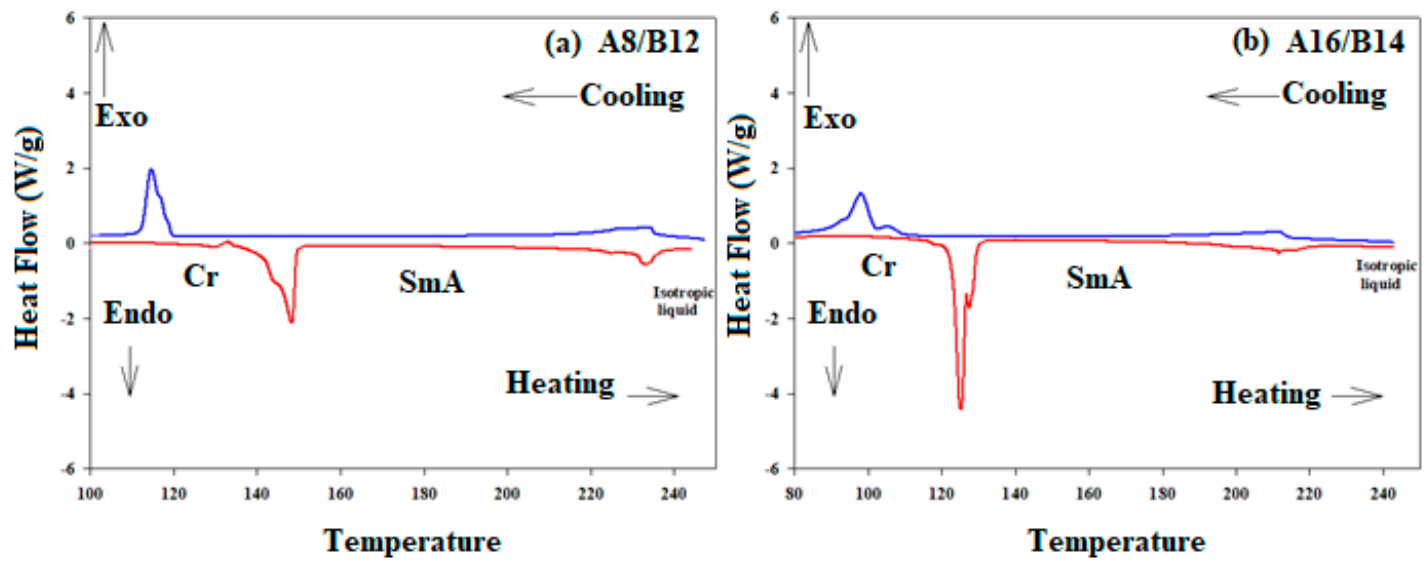

Figure 2. Differential scanning calorimetry (DSC) curves upon the second heating/cooling cycles with rate of $10^{\circ} \mathrm{C} / \mathrm{min}$ for 1:1 SMHBCs (a) A8/B12 and (b) A16/B14.

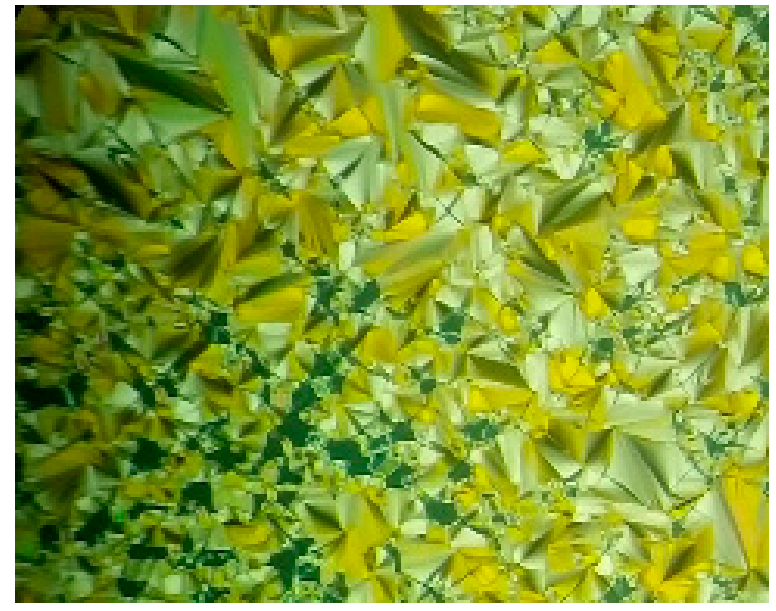

Figure 3. Polarized light microscopy (POM) SmA mesophase texture upon heating for 1:1 SMHBCs A16/B14 at $180^{\circ} \mathrm{C}$. 

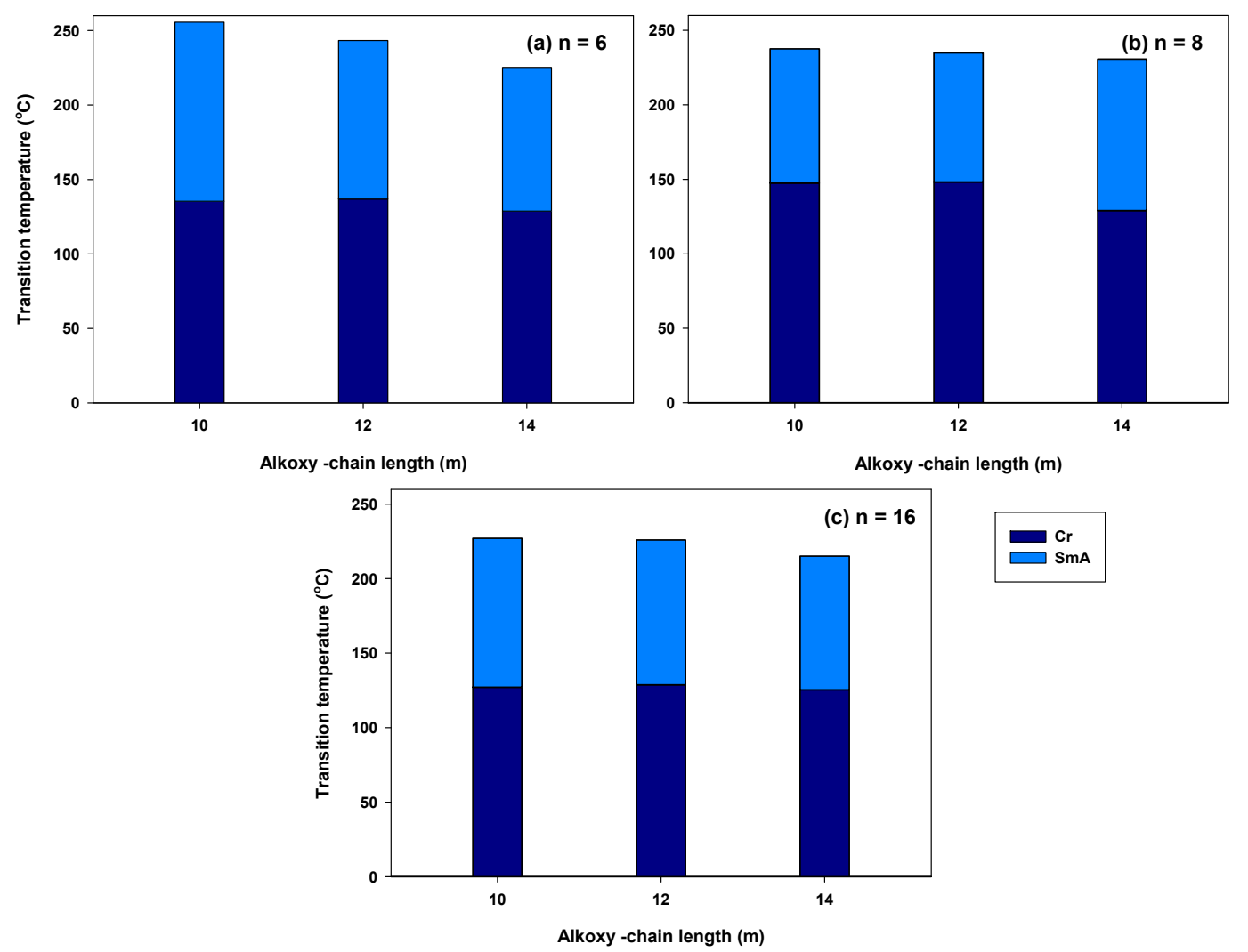

Figure 4. Graphical DSC transitions of 1:1 SMHBCs for (a) A6/Bm; (b) A8/Bm and (c) A16/Bm.

The azomethine benzoic acids (An) used to prepare the present SMHBCs form smectic A and narrow nematic $(\mathrm{N})$ phases depending on the length of their alkoxy chain terminals [64]. The azopyridine derivatives (Bm) are mesomorphic, exhibiting only SmA mesophases [19]. As can be seen from Table 1 and Figure 4, all formed calamitic SMHBCs (An/Bm) exhibit a broad enantiotropic range of SmA phases and the $\mathrm{N}$ phase is not observed for any prepared mixture. In addition, the melting temperatures of complexes have irregular values. Furthermore, the thermal stabilities of the SmA phase are decreased with increments in the length of the terminal chain. Generally, the mesogenic core and the length of the terminal chain of the H-donor molecule influence the stability of the formed mesophase. In addition, the polarity difference between $\mathrm{H}$-donors and $\mathrm{H}$-acceptors affects the strength of H-bonding interactions and enhances the molecular anisotropy, as well as promotes a broadening of the mesomorphic range [75]. However, the length of the terminal alkoxy chain of the mixture does not affect the polarity of each component.

In order to study the structural relationship in liquid crystalline materials further, theoretical calculations were performed by the DFT method (see Supplementary Materials) at B3LYP 6-31G (d, p) for selected series of the SMHBCs An/Bm to show the chain length effect of the acid and the base moieties. Evidence for the geometrical stability of all SMHBCs is the absence of imaginary frequencies. Although these calculations offer an expectation of the favored molecular structure in the gas phase, the existence of these derivatives in a liquid crystalline condensed phase means that the least energy might be changed and the more lengthened species with the longer chain length will be preferred [76]. Figure 5 shows the most favorable geometries of the H-bonded complexes $\mathbf{A n} / \mathbf{B m}$. 

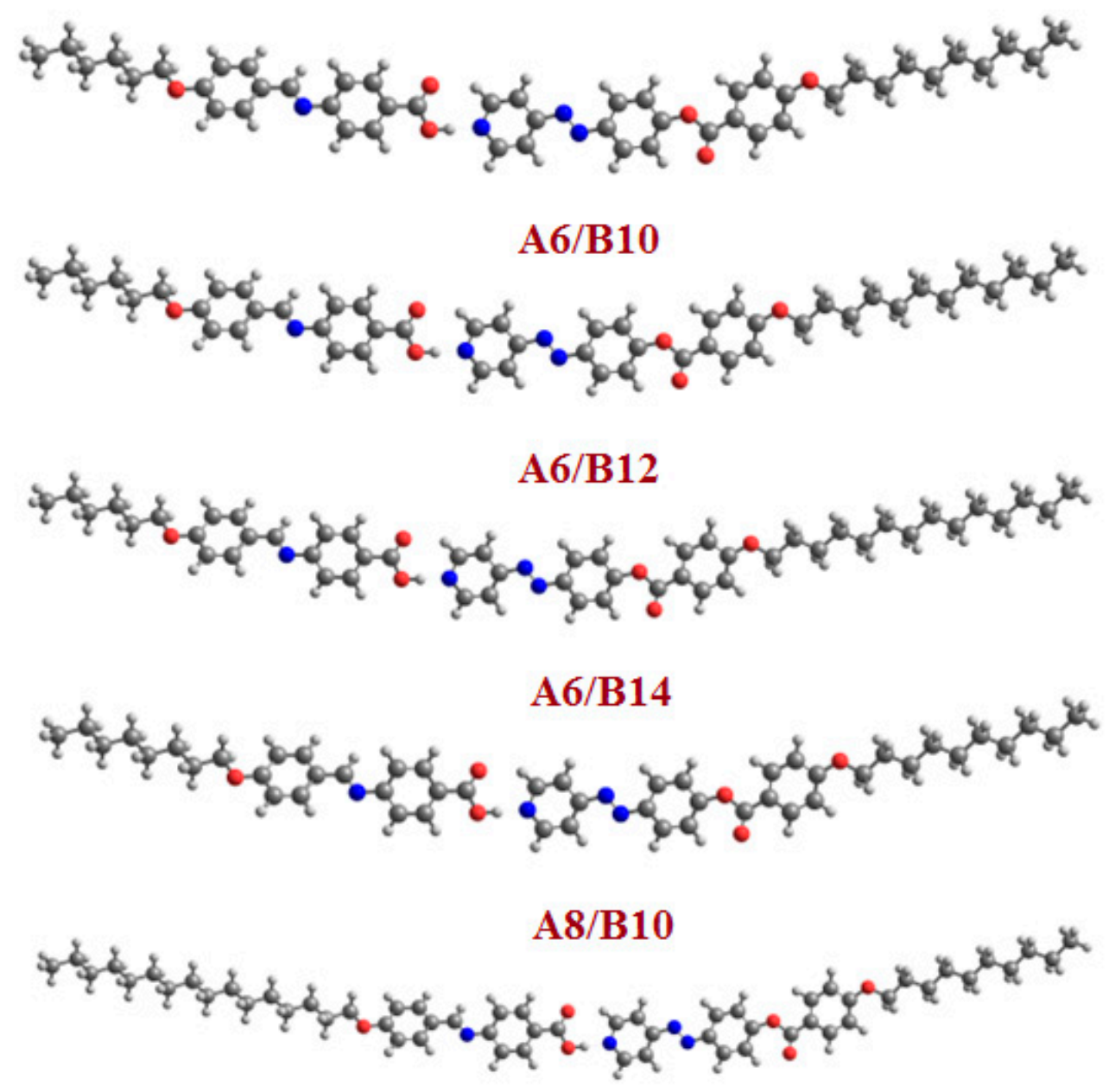

A16/B10

Figure 5. Calculated molecular geometrical structure of SMHBCs An/Bm.

Since both components of the hydrogen-bonded complex are completely in its planar geometry, their SMHBCs are also linear with very little bending. Figure 5 emphasizes that the length of the chains does not significantly affect their structural geometries. However, this small structure change could affect the mesomorphic behavior of liquid crystal complexes, which is highly dependent on the terminal length of wings [31]. SmA transition peaks (Figure 2) are affected by increasing the order parameter coupling during liquid crystal mixing that leads to broadening their peak transition in some cases [77]. Mesomorphic stability of the prepared 1:1 supramolecular complexes An/Bm decreases in the order An/B10 $>$ An/B12 $>$ An/B14, while the mesophase ranges change with the length of the terminal alkoxy chains. The $\mathbf{A 6} / \mathbf{B m}$ series showed an SmA phase with a wide range for the complex A6/B10 $\left(\sim 120.2^{\circ} \mathrm{C}\right)$ and a narrow range for A6/B14 $\left(\sim 96.5^{\circ} \mathrm{C}\right)$. For series A8/Bm, the highest range was observed for the complex A8/B14 $\left(\sim 101.7^{\circ} \mathrm{C}\right)$ while the lowest value was observed for A8/B12 $\left(\sim 86.5^{\circ} \mathrm{C}\right)$. Finally, the A16/Bm set exhibit a higher mesomorphic range for A16/B10 $\left(\sim 100.0^{\circ} \mathrm{C}\right)$ and a lower one for the $\mathbf{A 6} / \mathbf{B} 14\left(\sim 89.8^{\circ} \mathrm{C}\right)$ mixture.

\subsection{Thermal Parameters}

The projected thermal factors were predicted by DFT by using the same method and base set for both chain lengths of the acid and the base component of the prepared H-bonded complexes $\mathbf{A n} / \mathbf{B m}$, and the results are presented in Table 2. The results of the calculated thermal parameters revealed that there is no significant effect of the chain length of the acid or the base component on the estimated theoretical thermal stability, compare A6/B12 and A8/B10. These complexes are of the same length, 
with different lengths with respect to the acid and the base and they showed the same energy with $\Delta \mathrm{E}=0.0082 \mathrm{kcal} / \mathrm{mole}$. However, as could be expected, the longer chain length affords highly stable molecules. The extra stability could be explained in terms of a high degree of packing with longer chain lengths. The increase in the length of the alkoxy chains of individuals enhances the calculated stability of the mixtures. The longer terminal length increases the Van der Waals interactions of the flexible chains and thus lowers the estimated energy of the complexes.

Table 2. Thermal parameters (Hartree/particle) of both conformers of the H-bonded complexes An/Bm.

\begin{tabular}{cccccc}
\hline Parameter & A6/B10 & A6/B12 & A6/B14 & A8/B10 & A16/B10 \\
\hline$E_{\text {corr }}$ & 0.957322 & 1.014402 & 1.071444 & 1.014393 & 1.242606 \\
\hline ZPVE & -2532.136516 & -2610.703606 & -2689.270726 & -2610.703625 & -2924.972062 \\
\hline$E_{\text {tot }}$ & -2532.078335 & -2610.642704 & -2689.207085 & -2610.642717 & -2924.900273 \\
\hline$H$ & -2532.077391 & -2610.641759 & -2689.206140 & -2610.641773 & -2924.899329 \\
\hline$G$ & -2532.246843 & -2610.818015 & -2689.389523 & -2610.818111 & -2925.103243
\end{tabular}

Abbreviations; ZPVE: Sum of electronic and zero-point energies; $\mathrm{E}_{\text {tot }}$ : Sum of electronic and thermal energies; $\mathrm{H}$ : Sum of electronic and thermal enthalpies; G: Sum of electronic and thermal free energies.

The alteration of the mesophase behavior and temperature ranges $(\Delta \mathrm{T})$ for the stable SMHBCs An/Bm for alkoxy chain length are summarized in Table 3. It is obvious from Table 3 that the total smectic mesophase range and stability are decreased with alkoxy chain length either of the acid or the base. Moreover, the high dipole moment of the H-bonded complex could be an illustration of the formation of the smectic mesophase. The high dipole moment of the compounds enhances the molecular packing of the compounds in a highly ordered smectic mesophase. The lateral molecular interaction enhancement that is facilitated by the high dipole moment permits the smectic mesophase to be predominant.

Table 3. Dipole moment $(\mu)$, polarizability $(\alpha)$ and the mesophase parameters of SMHBCs An/Bm.

\begin{tabular}{cccccc}
\hline System & A6/B10 & A6/B12 & A6/B14 & A8/B10 & A16/B10 \\
\hline $\mathrm{T}_{\mathrm{Cr}-\mathrm{SmA}}$ & 135.4 & 136.8 & 128.8 & 147.4 & 127.1 \\
\hline $\mathrm{T}_{\text {SmA-I }}$ & 255.6 & 243.2 & 225.3 & 237.5 & 227.1 \\
\hline$\Delta \mathrm{S}_{\text {SmA-I }} / \mathrm{R}$ & 1.56 & 1.9 & 1.43 & 1.57 & 2.18 \\
\hline$\Delta \mathrm{T} c$ & 120.2 & 106.4 & 96.5 & 90.1 & 100 \\
\hline$\mu$ Total & 7.72 & 7.71 & 7.69 & 7.66 & 7.61 \\
\hline Polarizability $\alpha$ & 719.44 & 743.29 & 767.05 & 743.74 & 839.47 \\
\hline
\end{tabular}

As shown in Figures 6 and 7, the predicted polarizability of the H-bonded supramolecular complexes $\mathbf{A n} / \mathbf{B m}$ is significantly affected by the length of the alkoxy chain on the acid and base components. Increments in the alkoxy chain length increases the H-donor impact on the polarizability successively. The increment in the alkoxy chains resulted in higher space filling and so increased the polarizability. Alternatively, the dependence of the mesophase thermal stability on the polarizability is shown in Figures 6 and 7. The increments in the polarizability accordingly decreases the mesophase stability and its range. The smectic mesophase range and stability decrease with longer chain lengths, where, with the elongation of the chain lengths, the enhanced mesophase gradually became unstable due to the steric aspect. Moreover, that abnormal trend proposes that the geometrical structure alterations play a significant role. This behavior could be attributed to the dual role of increments in the length of the terminal alkoxy chain that led to an enhancement of the shape anisotropy of the complex, thus diluting the intermolecular interaction between the mesogenic parts [78,79]. Furthermore, the steric effect impacts the stability and the range of the mesophase rather than the polarizability, 
which has a different trend. It is clear that we could control the characteristics of the H-bonding, which could improve the properties of the individual components, by changing the parameters that are needed for special applications, such as the polarizability of the liquid crystalline material to be suitable for electro-optical applications [80-82].

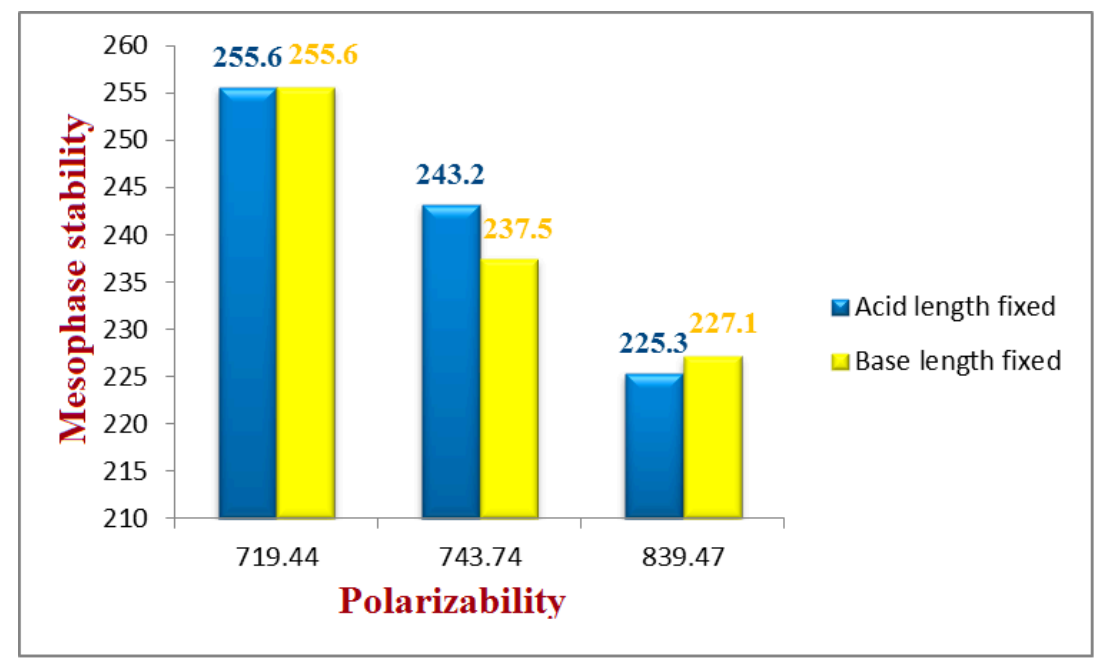

Figure 6. The relationship between the polarizability of the SMHBCs $(\mathbf{A n} / \mathbf{B m})$ and the total mesophase stability.

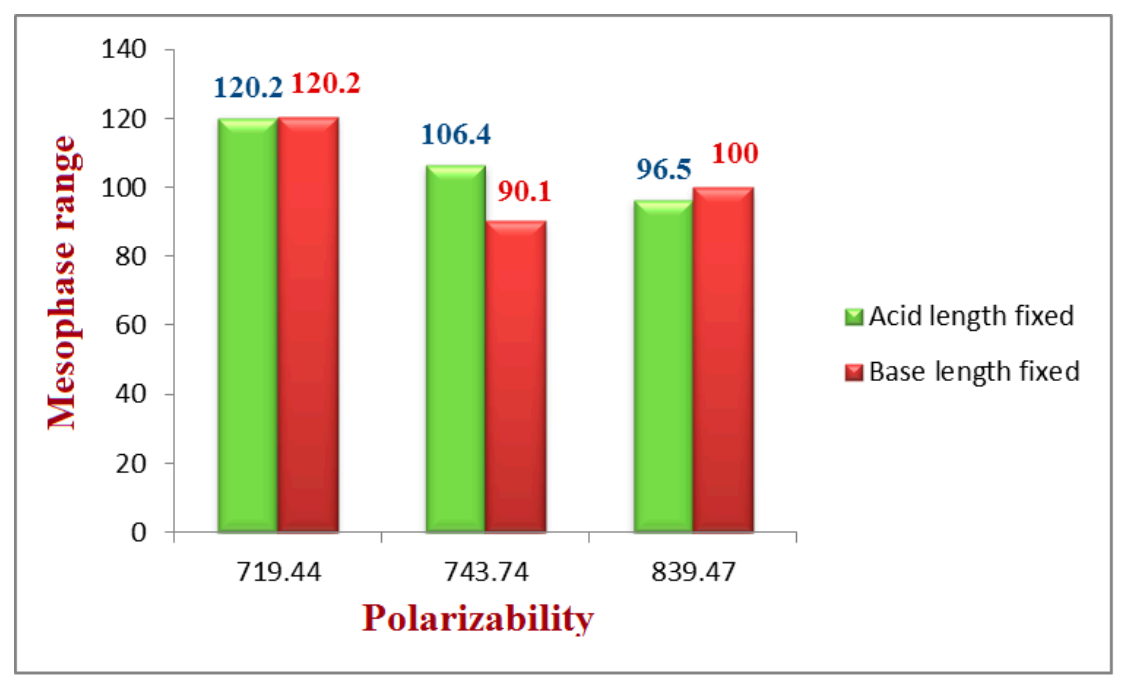

Figure 7. The relationship between the polarizability of the SMHBCs (An/Bm) and the total mesophase range.

\subsection{Frontier Molecular Orbitals (FMOs) and Polarizability}

Figures 8 and 9 demonstrate the predictable plots of the FMOs' highest occupied molecular orbital (HOMO) and the lowest unoccupied one (LUMO of the prepared SMHBCs An/Bm. As shown from the figures, it is obvious that the electron densities in the sites that participate in the formation of the HOMOs of the prepared SMHBCs showed sharing of the phenyl ring of the alkoxy acid in the formation of their HOMOs with the predominance of the pyridyl base in the formation of their LUMOs. Moreover, there was no obvious effect of the length of the alkoxy group of either the base or the acid on the location of the electron density of the FMOs. The energy difference between the FMOs could be used in the prediction of the ability of electron transformation from HOMO to LUMO during any electronic excitation process. It is clear from Table 4 that there is no significant impact of the alkoxy chain on the energy difference between the frontier orbitals. The global softness $(\mathrm{S})=\mathbf{1} / \Delta \mathrm{E}$ is the parameter that predicts the polarizability and the sensitivity of materials for the photoelectric property. 


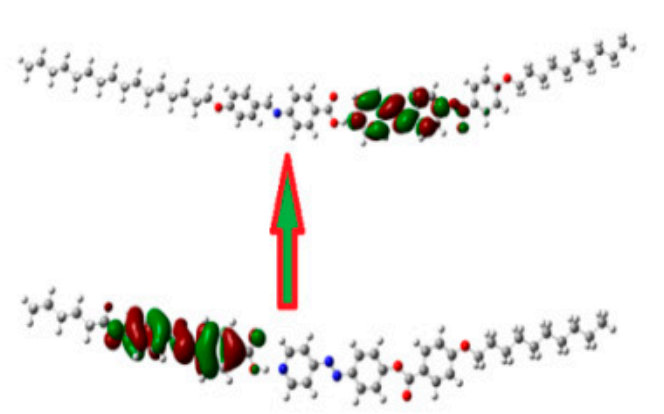

A6/B10

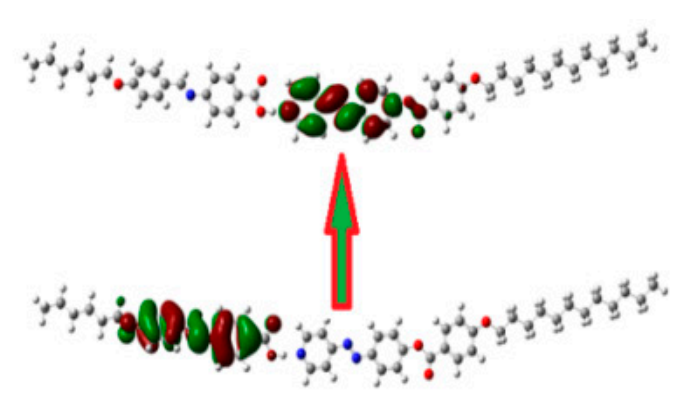

A6/B12

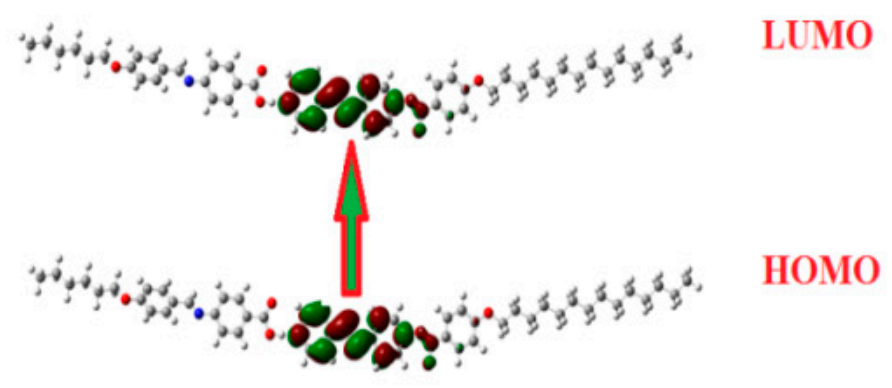

A6/B14

Figure 8. The estimated plots for frontier molecular orbitals of A6/Bm SMHBC conformers.

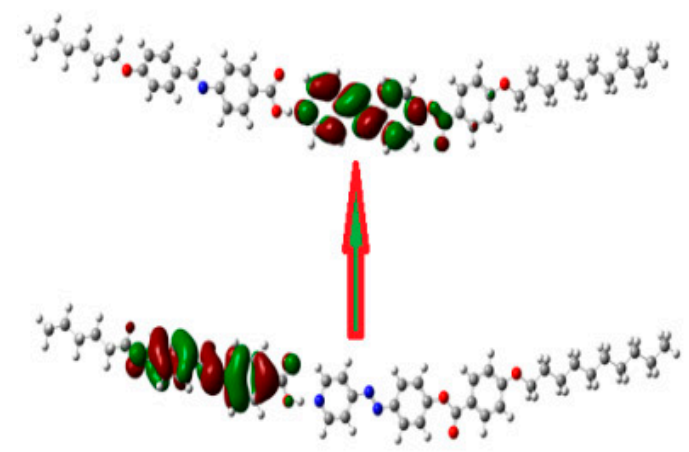

A6/B10

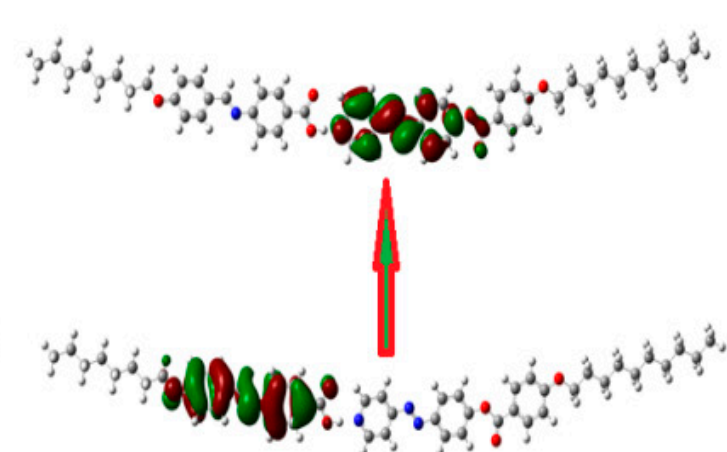

A8/B10

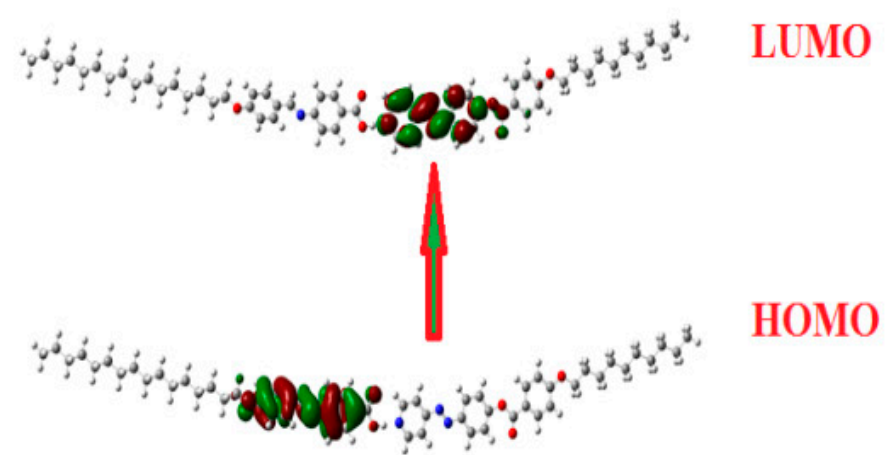

$\mathrm{A} 16 / \mathrm{B} 10$

Figure 9. The estimated plots for frontier molecular orbitals of SMHBCs $\mathbf{A n} / \mathbf{B m}$. 
Table 4. Frontier Molecular Orbitals (FMO) energies a.u., polarizability $\alpha$, and dipole moment $\mu$ (Debye) of conformers of the di-nicotinate base and SMHBCs An/Bm.

\begin{tabular}{lccccc}
\hline \multicolumn{1}{c}{ Parameter } & A6/B10 & A6/B12 & A6/B14 & A8/B10 & A16/B10 \\
\hline E $_{\text {LUMO }}$ & -0.11545 & -0.11543 & -0.11542 & -0.11541 & -0.11530 \\
\hline $\mathrm{E}_{\text {HOMO }}$ & -0.21456 & -0.21455 & -0.21454 & -0.21457 & -0.21450 \\
\hline$\Delta$ E $_{\text {HOMO-LUMO }}$ & 0.09911 & 0.09912 & 0.09912 & 0.09916 & 0.09920 \\
\hline S Softness & 10.090 & 10.089 & 10.089 & 10.085 & 10.081 \\
\hline
\end{tabular}

\subsection{Molecular Electrostatic Potential (MEP)}

The simulation of the distribution of charges in molecular electrostatic potential (MEP) of the structure of the SMHBCs An/Bm was done by the same method and with the same basis sets (Figure 10). The red region is considered the negatively charged atomic center and was estimated to be localized on the ester linkage of the H-bonds of the alkoxy acid carboxylate. On the other hand, part of the base and the electron donor alkoxy chains of the acid were expected to be blue regions and show atomic sites of the lowest negative charge. As shown in Figure 10, the length of the alkoxy group of the acid, as well as the base, does not affect the distribution of the charge mapping for $\mathbf{A n} / \mathbf{B m}$.

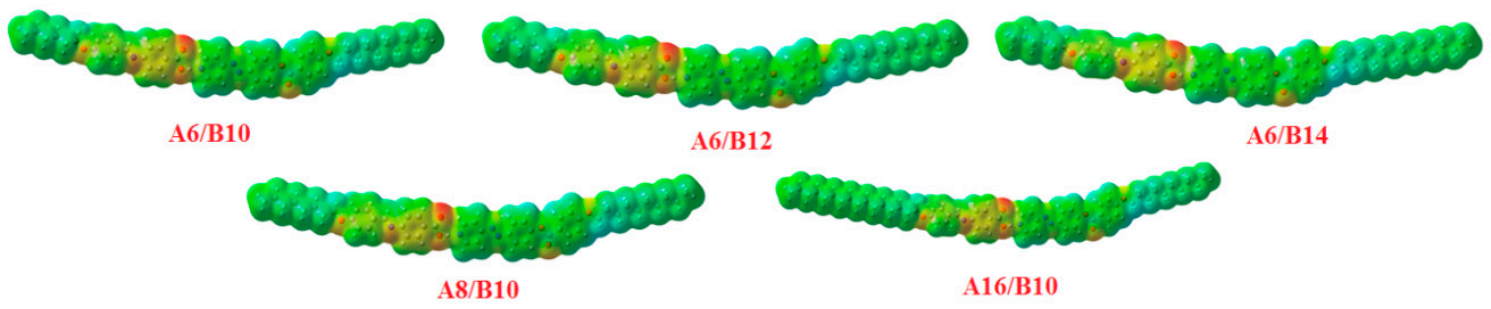

Figure 10. Molecular Electrostatic Potential (MEP) for investigated complexes An/Bm.

\subsection{Entropy Changes}

The transition entropy changes $(\Delta S / R)$ of all prepared 1:1 SMHBCs were estimated from DSC measurements and are collected in Table 1. Small magnitudes of entropy changes for an SmA-I transition are observed in addition to an irregular trend for all series with the length of the terminal flexible alkoxy groups. According to previous reports [83-86], the lower values of estimated entropy changes for conventional mesogens of low molar mass are due to the thermal cis/trans isomerization of the linkage. Furthermore, the enhanced shape anisotropy of molecules to pack more closely in the liquid crystal phase will result in higher transition temperatures and affect the change of the entropy [87].

\section{Conclusions}

New five-membered rings of 1:1 SMHBLC complexes were reported. Mesomorphic and geometrical aspects were investigated. Optical measurements were carried out by DSC and POM, whereas the geometrical characterizations were performed by the DFT method. Mesomorphic investigations revealed that the mesogenic core (azomethine group) of the acid molecule has a role in the formation of enantiotropic SmA mesophase with wide smectogenic range and high thermal stability. DFT results revealed that the geometrical shapes of the present complexes are rod-like (calamitic structural shape). Moreover, the theatrical investigations revealed that the high dipole moment of the H-bonded complex illustrates the enhancement of the smectic mesophases. On the other hand, increasing the alkoxy chain length enhances the acid component and affects the polarizability successively. Finally, there was no obvious effect of the length of alkoxy group of either the base or the acid, the position of the electron density of the FMOs nor their energy gap. 
Supplementary Materials: The following are available online at http://www.mdpi.com/2073-4352/10/9/795/s1. References [88-90] are cited in the supplementary materials.

Author Contributions: Data curation, L.A.A.-M., H.A.A., M.H. and K.A.A.A.-O.; Formal analysis, L.A.A.-M., L.A.A. and M.H.; Funding acquisition, L.A.A.-M., L.A.A. and H.A.A.; Methodology, L.A.A.-M., H.A.A., M.H. and K.A.A.A.-O.; Project administration, M.H.; Resources, L.A.A. and H.A.A.; Software, M.H.; Writing-original draft, H.A.A. and M.H.; Writing-review and editing, H.A.A. and M.H. All authors have read and agreed to the published version of the manuscript.

Funding: This research received no external funding.

Acknowledgments: This research was funded by the Deanship of Scientific Research at Princess Nourah bint Abdulrahman University through the Fast-track Research Funding Program.

Conflicts of Interest: The authors declare no conflict of interest.

\section{References}

1. Fairhurst, C.; Fuller, S.; Gray, J.; Holmes, M.; Tiddy, G. Handbook of Liquid Crystals; Demus, D., Goodby, J., Gray, G.W., Spiess, H.-W., Vill, V., Eds.; Wiley-VCH: New York, NY, USA, 1998; p. 341.

2. Bennet, G.; Jones, B. Mesomorphism and polymorphism of some p-alkoxybenzoic and p-alkoxy-cinnamic acids. J. Chem. Soc. 1939, 420-425. [CrossRef]

3. Kato, T.; Frechet, J.M. A new approach to mesophase stabilization through hydrogen bonding molecular interactions in binary mixtures. J. Am. Chem. Soc. 1989, 111, 8533-8534. [CrossRef]

4. Kato, T. Hydrogen-bonded liquid crystals: Molecular self-assembly for dynamically functional materials. In Molecular Self-Assembly Organic Versus Inorganic Approaches; Springer: Berlin/Heidelberg, Germany, 2000; pp. 95-146.

5. Paleos, C.M.; Tsiourvas, D. Supramolecular hydrogen-bonded liquid crystals. Liq. Cryst. 2001, 28, $1127-1161$. [CrossRef]

6. Demus, D.; Goodby, J.W.; Gray, G.W.; Spiess, H.W.; Vill, V. Handbook of Liquid Crystals, Volume 2A: Low Molecular Weight Liquid Crystals I: Calamitic Liquid Crystals; John Wiley \& Sons: Hoboken, NJ, USA, 2011.

7. Kato, T.; Kato, T.; Fréchet, J.M.; Uryu, T.; Kaneuchi, F.; Jin, C.; Fréchet, J.M. Hydrogen-bonded liquid crystals built from hydrogen-bonding donors and acceptors Infrared study on the stability of the hydrogen bond between carboxylic acid and pyridyl moieties. Liq. Cryst. 2006, 33, 1429-1437. [CrossRef]

8. Nguyen, H.L.; Horton, P.N.; Hursthouse, M.B.; Legon, A.C.; Bruce, D.W. Halogen bonding: A new interaction for liquid crystal formation. J. Am. Chem. Soc. 2004, 126, 16-17. [CrossRef]

9. Metrangolo, P.; Präsang, C.; Resnati, G.; Liantonio, R.; Whitwood, A.C.; Bruce, D.W. Fluorinated liquid crystals formed by halogen bonding. Chem. Commun. 2006, 31, 3290-3292. [CrossRef] [PubMed]

10. Präsang, C.; Nguyen, H.L.; Horton, P.N.; Whitwood, A.C.; Bruce, D.W. Trimeric liquid crystals assembled using both hydrogen and halogen bonding. Chem. Commun. 2008, 46, 6164-6166. [CrossRef] [PubMed]

11. Alaasar, M.; Poppe, S.; Tschierske, C. Photoresponsive halogen bonded polycatenar liquid crystals. J. Mol. Liq. 2019, 277, 233-240. [CrossRef]

12. Wang, H.; Bisoyi, H.K.; Wang, L.; Urbas, A.M.; Bunning, T.J.; Li, Q. Photochemically and Thermally Driven Full-Color Reflection in a Self-Organized Helical Superstructure Enabled by a Halogen-Bonded Chiral Molecular Switch. Angew. Chem. Int. Ed. 2018, 57, 1627-1631. [CrossRef]

13. Saccone, M.; Catalano, L. Halogen bonding beyond crystals in materials science. J. Phys. Chem. B 2019, 123, 9281-9290. [CrossRef]

14. Dong, R.; Zhou, Y.; Huang, X.; Zhu, X.; Lu, Y.; Shen, J. Functional supramolecular polymers for biomedical applications. Adv. Mater. 2015, 27, 498-526. [CrossRef] [PubMed]

15. Yang, Y.; Urban, M.W. Self-healing polymeric materials. Chem. Soc. Rev. 2013, 42, 7446-7467. [CrossRef] [PubMed]

16. Liu, K.; Kang, Y.; Wang, Z.; Zhang, X. 25th anniversary article: Reversible and adaptive functional supramolecular materials: “Noncovalent interaction" matters. Adv. Mater. 2013, 25, 5530-5548. [CrossRef] [PubMed]

17. Yan, X.; Wang, F.; Zheng, B.; Huang, F. Stimuli-responsive supramolecular polymeric materials. Chem. Soc. Rev. 2012, 41, 6042-6065. [CrossRef] 
18. González-Rodríguez, D.; Schenning, A.P. Hydrogen-bonded supramolecular $\pi$-functional materials. Chem. Mater. 2011, 23, 310-325. [CrossRef]

19. Naoum, M.; Fahmi, A.; Alaasar, M. Supramolecular hydrogen-bonded liquid crystals formed from 4-(4'-pyridylazophenyl)-4" ${ }^{\prime \prime}$-alkoxy benzoates and 4-substituted benzoic acids. Mol. Cryst. Liq. Cryst. 2008, 487, 74-91. [CrossRef]

20. Alnoman, R.B.; Ahmed, H.A.; Hagar, M.; Abu Al-Ola, K.A.; Alrefay, B.S.; Haddad, B.A.; Albalawi, R.F.; Aljuhani, R.H.; Aloqebi, L.D.; Alsenani, S.F. Induced phases of new H-bonded supramolecular liquid crystal complexes; Mesomorphic and geometrical estimation. Molecules 2020, 25, 1549. [CrossRef]

21. Gimeno, N.; Ros, M.B.; Serrano, J.L.; de la Fuente, M.R. Hydrogen-Bonded Banana Liquid Crystals. Angew. Chem. 2004, 116, 5347-5350. [CrossRef]

22. Gimeno, N.; Ros, M.B.; Serrano, J.L.; De la Fuente, M.R. Noncovalent interactions as a tool to design new bent-core liquid-crystal materials. Chem. Mater. 2008, 20, 1262-1271. [CrossRef]

23. Alaasar, M.; Tschierske, C.; Prehm, M. Hydrogen-bonded supramolecular complexes formed between isophthalic acid and pyridine-based derivatives. Liq. Cryst. 2011, 38, 925-934. [CrossRef]

24. Wang, J.; Shi, Y.; Yang, K.; Wei, J.; Guo, J. Stabilization and optical switching of liquid crystal blue phase doped with azobenzene-based bent-shaped hydrogen-bonded assemblies. Rsc Adv. 2015, 5, 67357-67364. [CrossRef]

25. Korkmaz, B.; Canli, N.Y.; Özdemir, Z.G.; Okutan, M.; Gursel, Y.H.; Sarac, A.; Şenkal, B.F. Synthesis and electrical properties of hydrogen bonded liquid crystal polymer. J. Mol. Liq. 2016, 219, 1030-1035. [CrossRef]

26. Pfletscher, M.; Wölper, C.; Gutmann, J.S.; Mezger, M.; Giese, M. A modular approach towards functional supramolecular aggregates-subtle structural differences inducing liquid crystallinity. Chem. Commun. 2016, 52, 8549-8552. [CrossRef] [PubMed]

27. Alaasar, M.; Tschierske, C. Nematic phases driven by hydrogen-bonding in liquid crystalline nonsymmetric dimers. Liq. Cryst. 2019, 46, 124-130. [CrossRef]

28. Walker, R.; Pociecha, D.; Abberley, J.; Martinez-Felipe, A.; Paterson, D.; Forsyth, E.; Lawrence, G.; Henderson, P.; Storey, J.; Gorecka, E. Spontaneous chirality through mixing achiral components: A twist-bend nematic phase driven by hydrogen-bonding between unlike components. Chem. Commun. 2018, 54, 3383-3386. [CrossRef]

29. Alaasar, M.; Poppe, S.; Dong, Q.; Liu, F.; Tschierske, C. Mirror symmetry breaking in cubic phases and isotropic liquids driven by hydrogen bonding. Chem. Commun. 2016, 52, 13869-13872. [CrossRef]

30. Yagai, S.; Kitamura, A. Recent advances in photoresponsive supramolecular self-assemblies. Chem. Soc. Rev. 2008, 37, 1520-1529. [CrossRef]

31. Ahmed, H.A.; Hagar, M.; Alhaddad, O.A.; Zaki, A.A. Optical and geometrical characterizations of non-linear supramolecular liquid crystal complexes. Crystals 2020, 10, 701. [CrossRef]

32. Yeap, G.-Y.; Hng, T.-C.; Yeap, S.-Y.; Gorecka, E.; Ito, M.M.; Ueno, K.; Okamoto, M.; Mahmood, W.A.K.; Imrie, C.T. Why do non-symmetric dimers intercalate? The synthesis and characterisation of the $\alpha$-(4-benzylidene-substituted-aniline-4'-oxy)- $\omega$-(2-methylbutyl-4'-(4' -phenyl) benzoateoxy) alkanes. Liq. Cryst. 2009, 36, 1431-1441. [CrossRef]

33. Zaremba, M.; Siksnys, V. Molecular scissors under light control. Proc. Natl. Acad. Sci. USA 2010, 107, 1259-1260. [CrossRef]

34. Lee, K.M.; White, T.J. Photomechanical response of composite structures built from azobenzene liquid crystal polymer networks. Polymers 2011, 3, 1447-1457. [CrossRef]

35. Garcia-Amorós, J.; Reig, M.; Castro, M.C.R.; Cuadrado, A.; Raposo, M.M.M.; Velasco, D. Molecular photo-oscillators based on highly accelerated heterocyclic azo dyes in nematic liquid crystals. Chem. Commun. 2014, 50, 6704-6706. [CrossRef] [PubMed]

36. Alaasar, M. Azobenzene-containing bent-core liquid crystals: An overview. Liq. Cryst. 2016, 43, $2208-2243$. [CrossRef]

37. Bisoyi, H.K.; Li, Q. Light-driven liquid crystalline materials: From photo-induced phase transitions and property modulations to applications. Chem. Rev. 2016, 116, 15089-15166. [CrossRef] [PubMed]

38. Sunil, B.; Srinatha, M.; Shanker, G.; Hegde, G.; Alaasar, M.; Tschierske, C. Effective tuning of optical storage devices using photosensitive bent-core liquid crystals. J. Mol. Liq. 2020, 304, 112719. [CrossRef] 
39. Nafee, S.S.; Hagar, M.; Ahmed, H.A.; Alhaddad, O.; El-Shishtawy, R.M.; Raffah, B.M. New two rings Schiff base liquid crystals; ball mill synthesis, mesomorphic, Hammett and DFT studies. J. Mol. Liq. 2020, 299, 112161. [CrossRef]

40. Hagar, M.; Ahmed, H.; Alhaddadd, O. DFT calculations and mesophase study of coumarin esters and its azoesters. Crystals 2018, 8, 359. [CrossRef]

41. Alnoman, R.B.; Hagar, M.; Ahmed, H.A.; Naoum, M.M.; Sobaih, H.A.; Almshaly, J.S.; Haddad, M.M.; Alhaisoni, R.A.; Alsobhi, T.A. Binary Liquid Crystal Mixtures Based on Schiff Base Derivatives with Oriented Lateral Substituents. Crystals 2020, 10, 319. [CrossRef]

42. Hagar, M.; Ahmed, H.; Aouad, M. Mesomorphic and DFT diversity of Schiff base derivatives bearing protruded methoxy groups. Liq. Cryst. 2020. [CrossRef]

43. Demus, D.; Goodby, J.; Gray, G.W.; Spiess, H.-W.; Vill, V. Handbook of Liquid Crystals; Wiley-VCHI Press: Weinheim, Germany, 1998; Volume 1.

44. Ahmed, H.; Hagar, M.; Alaasar, M.; Naoum, M. Wide nematic phases induced by hydrogen-bonding. Liq. Cryst. 2018. [CrossRef]

45. Ahmed, H.; Hagar, M.; Aljuhani, A. Mesophase behavior of new linear supramolecular hydrogen-bonding complexes. RSC Adv. 2018, 8, 34937-34946. [CrossRef]

46. Ahmed, H.; Naoum, M. Mesophase behaviour of azobenzene-based angular supramolecular hydrogen-bonded liquid crystals. Liq. Cryst. 2016, 43, 222-234. [CrossRef]

47. Goodby, J.W.; Collings, P.J.; Kato, T.; Tschierske, C.; Gleeson, H.; Raynes, P.; Vill, V. Handbook of Liquid Crystals, 8 Volume Set; John Wiley \& Sons: Hoboken, NJ, USA, 2014; Volume 2.

48. Tschierske, C. Development of structural complexity by liquid-crystal self-assembly. Angew. Chem. Int. Ed. 2013, 52, 8828-8878. [CrossRef]

49. Armstrong, G.; Buggy, M. Hydrogen-bonded supramolecular polymers: A literature review. J. Mater. Sci. 2005, 40, 547-559. [CrossRef]

50. Walker, R.; Pociecha, D.; Crawford, C.A.; Storey, J.M.; Gorecka, E.; Imrie, C.T. Hydrogen bonding and the design of twist-bend nematogens. J. Mol. Liq. 2020, 303, 112630. [CrossRef]

51. Saccone, M.; Pfletscher, M.; Dautzenberg, E.; Dong, R.Y.; Michal, C.A.; Giese, M. Hydrogen-bonded liquid crystals with broad-range blue phases. J. Mater. Chem. C 2019, 7, 3150-3153. [CrossRef]

52. Martinez-Felipe, A.; Velayutham, T.S.; Aripin, N.F.K.; Yusoff, M.; Farquharson, E.; Hashim, R. Glycolipids from natural sources: Dry liquid crystal properties, hydrogen bonding and molecular mobility of Palm Kernel oil mannosides. Liq. Cryst. 2020. [CrossRef]

53. Tuchband, M.R.; Paterson, D.A.; Salamończyk, M.; Norman, V.A.; Scarbrough, A.N.; Forsyth, E.; Garcia, E.; Wang, C.; Storey, J.M.; Walba, D.M. Distinct differences in the nanoscale behaviors of the twist-bend liquid crystal phase of a flexible linear trimer and homologous dimer. Proc. Natl. Acad. Sci. USA 2019, 116, 10698-10704. [CrossRef] [PubMed]

54. Saccone, M.; Pfletscher, M.; Kather, S.; Wölper, C.; Daniliuc, C.; Mezger, M.; Giese, M. Improving the mesomorphic behaviour of supramolecular liquid crystals by resonance-assisted hydrogen bonding. J. Mater. Chem. C 2019, 7, 8643-8648. [CrossRef]

55. Nafee, S.S.; Ahmed, H.A.; Hagar, M. New architectures of supramolecular H-bonded liquid crystal complexes based on dipyridine derivatives. Liq. Cryst. 2020. [CrossRef]

56. Alnoman, R.B.; Hagar, M.; Ahmed, H.A.; Abu Al-Ola, K.A.; Naoum, M.M.; Al-Elati, F.; Abdullah Zaid, Y.; Alsharif, A.; Al-Juhani, Y.; Abulrhelh, A. Characterization of new H-bonded liquid crystalline complexes based on iminophenyl nicotinate. Crystals 2020, 10, 499. [CrossRef]

57. Al-Mutabagani, L.A.; Alshabanah, L.A.; Ahmed, H.A.; Hagar, M.; Al-Ola, K.A.A. New symmetrical U-and wavy-shaped supramolecular H-bonded systems; geometrical and mesomorphic approaches. Molecules 2020, 25, 1420. [CrossRef] [PubMed]

58. Abdullah Alshabanah, L.; Al-Mutabagani, L.A.; Ahmed, H.A.; Hagar, M. Induced wide nematic phase by seven-ring supramolecular H-bonded systems: Experimental and computational evaluation. Molecules 2020, 25, 1694. [CrossRef] [PubMed]

59. Hagar, M.; Ahmed, H.A.; El-Sayed, T.H.; Alnoman, R. Mesophase behavior and DFT conformational analysis of new symmetrical diester chalcone liquid crystals. J. Mol. Liq. 2019, 285, 96-105. [CrossRef]

60. Alhaddad, O.; Ahmed, H.; Hagar, M. Experimental and Theoretical Approaches of New Nematogenic Chair Architectures of Supramolecular H-Bonded Liquid Crystals. Molecules 2020, 25, 365. [CrossRef] 
61. Alnoman, R.B.; Hagar, M.; Parveen, S.; Ahmed, H.A.; Knight, J.G. Computational and molecular docking approaches of a New axially chiral BODIPY fluorescent dye. J. Photochem. Photobiol. A Chem. 2020, 395, 112508. [CrossRef]

62. Nafee, S.S.; Ahmed, H.; Hagar, M. Theoretical, experimental and optical study of new thiophene-based liquid crystals and their positional isomers. Liq. Cryst. 2020. [CrossRef]

63. Hagar, M.; Ahmed, H.A.; Aljohani, G.; Alhaddad, O.A. Investigation of Some Antiviral N-Heterocycles as COVID 19 Drug: Molecular Docking and DFT Calculations. Int. J. Mol. Sci. 2020, 21, 3922. [CrossRef]

64. Nafee, S.S.; Hagar, M.; Ahmed, H.A.; El-Shishtawy, R.M.; Raffah, B.M. The synthesis of new thermal stable schiff base/ester liquid crystals: A computational, mesomorphic, and optical study. Molecules 2019, 24, 3032. [CrossRef]

65. Saunders, M.; Hyne, J.B. Study of hydrogen bonding in systems of hydroxylic compounds in carbon tetrachloride through the use of NMR. J. Chem. Phys. 1958, 29, 1319-1323. [CrossRef]

66. Hu, Y.; Shim, Y.; Oh, J.; Park, S.; Park, S.; Ishii, Y. Synthesis of 13C-, 15N-labeled graphitic carbon nitrides and NMR-based evidence of hydrogen-bonding assisted two-dimensional assembly. Chem. Mater. 2017, 29, 5080-5089. [CrossRef]

67. Lam, R.K.; Smith, J.W.; Saykally, R.J. Communication: Hydrogen Bonding Interactions in Water-Alcohol Mixtures from X-Ray Absorption Spectroscopy. J. Chem. Phys. 2016, 144, 191103. [CrossRef] [PubMed]

68. Pothoczki, S.; Pethes, I.; Pusztai, L.; Temleitner, L.; Csókás, D.; Kohara, S.; Ohara, K.; Bakó, I. Hydrogen bonding and percolation in propan-2-ol-water liquid mixtures: X-ray diffraction experiments and computer simulations. arXiv 2020, arXiv:2001.11923.

69. Martinez-Felipe, A.; Cook, A.G.; Abberley, J.P.; Walker, R.; Storey, J.M.; Imrie, C.T. An FT-IR spectroscopic study of the role of hydrogen bonding in the formation of liquid crystallinity for mixtures containing bipyridines and 4-pentoxybenzoic acid. RSC Adv. 2016, 6, 108164-108179. [CrossRef]

70. Martínez-Felipe, A.; Imrie, C.T. The role of hydrogen bonding in the phase behaviour of supramolecular liquid crystal dimers. J. Mol. Struct. 2015, 1100, 429-437. [CrossRef]

71. Paterson, D.A.; Martínez-Felipe, A.; Jansze, S.M.; TM Marcelis, A.; MD Storey, J.; Imrie, C.T. New insights into the liquid crystal behaviour of hydrogen-bonded mixtures provided by temperature-dependent FTIR spectroscopy. Liq. Cryst. 2015, 42, 928-939. [CrossRef]

72. Cleland, W.; Kreevoy, M.M. Low-barrier hydrogen bonds and enzymic catalysis. Science 1994, 264, $1887-1890$. [CrossRef]

73. Lizu, M.; Lutfor, M.; Surugau, N.; How, S.; Arshad, S.E. Synthesis and characterization of ethyl cellulose-based liquid crystals containing azobenzene chromophores. Mol. Cryst. Liq. Cryst. 2010, 528, 64-73. [CrossRef]

74. Ghanem, A.; Noel, C. FTIR investigation of two alkyl-p-terphenyl-4, $4^{\prime \prime}$-dicarboxylates in their crystalline, smectic and isotropic phases. Mol. Cryst. Liq. Cryst. 1987, 150, 447-472. [CrossRef]

75. Ahmed, H.; Naoum, M.; Saad, G. Mesophase behaviour of 1:1 mixtures of 4-n-alkoxyphenylazo benzoic acids bearing terminal alkoxy groups of different chain lengths. Liq. Cryst. 2016, 43, 1259-1267. [CrossRef]

76. Paterson, D.A.; Walker, R.; Abberley, J.P.; Forestier, J.; Harrison, W.T.; Storey, J.M.; Pociecha, D.; Gorecka, E.; Imrie, C.T. Azobenzene-based liquid crystal dimers and the twist-bend nematic phase. Liq. Cryst. 2017, 44, 2060-2078. [CrossRef]

77. Qian, S.; Iannacchione, G.S.; Finotello, D. Critical behavior of a smectic-A to nematic phase transition imbedded in a random network of voids. Phys. Rev. E 1998, 57, 4305. [CrossRef]

78. Imrie, C.; Taylor, L. The preparation and properties of low molar mass liquid crystals possessing lateral alkyl chains. Liq. Cryst. 1989, 6, 1-10. [CrossRef]

79. Ahmed, H.; Hagar, M.; El-Sayed, T.; Alnoman, R. Schiff base/ester liquid crystals with different lateral substituents: Mesophase behaviour and DFT calculations. Liq. Cryst. 2019, 46,1-11. [CrossRef]

80. Meredith, G.R.; VanDusen, J.; Williams, D.J. Optical and nonlinear optical characterization of molecularly doped thermotropic liquid crystalline polymers. Macromolecules 1982, 15, 1385-1389. [CrossRef]

81. Khoo, I.-C.; Wu, S.-T. Optics and Nonlinear Optics of Liquid Crystals; World Scientific: Singapore, 1993.

82. Chemla, D.S. Nonlinear Optical Properties of Organic Molecules and Crystals; Elsevier: Amsterdam, The Netherlands, 2012; Volume 1.

83. Imrie, C.; Karasz, F.; Attard, G. Comparison of the mesogenic properties of monomeric, dimeric, and side-chain polymeric liquid crystals. Macromolecules 1993, 26, 545-550. [CrossRef] 
84. Donaldson, T.; Staesche, H.; Lu, Z.; Henderson, P.; Achard, M.; Imrie, C. Symmetric and non-symmetric chiral liquid crystal dimers. Liq. Cryst. 2010, 37, 1097-1110. [CrossRef]

85. Henderson, P.A.; Niemeyer, O.; Imrie, C.T. Methylene-linked liquid crystal dimers. Liq. Cryst. 2001, 28, 463-472. [CrossRef]

86. Henderson, P.A.; Imrie, C.T. Methylene-linked liquid crystal dimers and the twist-bend nematic phase. Liq. Cryst. 2011, 38, 1407-1414. [CrossRef]

87. Henderson, P.; Cook, A.; Imrie, C. Oligomeric liquid crystals: From monomers to trimers. Liq. Cryst. 2004, 31, 1427-1434. [CrossRef]

88. Cammenga, H.K.; Eysel, W.; Gmelin, E.; Hemminger, W.; Höhne, G.W.; Sarge, S.M. The temperature calibration of scanning calorimeters: Part 2. Calibration substances. Thermochim. Acta 1993, 219, 333-342. [CrossRef]

89. Frisch, M.; Trucks, G.; Schlegel, H.B.; Scuseria, G.; Robb, M.; Cheeseman, J.; Scalmani, G.; Barone, V.; Mennucci, B.; Petersson, G. Gaussian 09, Revision A. 02; Gaussian Inc.: Wallingford, CT, USA, 2009; p. 200.

90. Dennington, R.; Keith, T.; Millam, J. GaussView, Version 5; Semichem Inc.: Shawnee Mission, KS, USA, 2009.

(C) 2020 by the authors. Licensee MDPI, Basel, Switzerland. This article is an open access article distributed under the terms and conditions of the Creative Commons Attribution (CC BY) license (http://creativecommons.org/licenses/by/4.0/). 